\title{
Acardiac-acephalus Twinning- A Very Rare Case Report
}

\author{
Parvez Ahmed *1, Nasrin Begum ${ }^{2}$, Mostofa Shamim Ahsan ${ }^{3}$, Mosharruf Hossain ${ }^{4}$, \\ Munshi Md. Arif Hosen ${ }^{5}$, Tasnim Ahmed ${ }^{6}$
}

\begin{abstract}
Introduction:This study highlights a very rare case which was related to abnormal monochorionic twinning status. Case Report: This case (a 28 year old pregnant woman) came at this institute for ultrasonographic evaluation of her pregnancy status. Her ultrasonographic results were consistent with acardiac-acephalus twinning condition (which is also known as, twin reversed arterial perfusion or TRAP sequence). Discussion: This monochorionic twin pregnancy is a severe form of twin-to-twin transfusion syndrome (TTTS) and severe TTTS has mortality rate of about $60-100 \%$. Conclusion: This case is very rare showing prevalence of about 1/35,000 overall pregnancies and accounting $1.0 \%$ of the monochorionic twin pregnancies.
\end{abstract}

Keywords: Acardiac-acephalus condition (or, TRAP sequence), Monochorionic twin pregnancy.

Number of Figure: 02; Number of References: 07; Number of Correspondence: 03.

\section{*1. Corresponding Author:}

\section{Dr. Parvez Ahmed}

SMO/Assistant Professor

Institute of Nuclear Medicine and Allied Sciences, Rajshahi, Bangladesh.

Email: drparvezahmed@yahoo.com

\section{Dr. Nasrin Begum}

$\mathrm{PMO} /$ Associate Professor

Institute of Nuclear Medicine and Allied Sciences, Rajshahi, Bangladesh.

\section{Dr. Mostofa Shamim Ahsan}

Director \& CMO/Professor

Institute of Nuclear Medicine and Allied Sciences, Rajshahi, Bangladesh.

\section{Dr. Mosharruf Hossain}

$\mathrm{PMO} /$ Associate Professor

Institute of Nuclear Medicine and Allied Sciences, Rajshahi, Bangladesh.

\section{Dr. Munshi Md. Arif Hosen}

SMO/Assistant Professor

Institute of Nuclear Medicine and Allied Sciences, Rajshahi, Bangladesh.

\section{Dr. Tasnim Ahmed}

SMO/Assistant Professor

Institute of Nuclear Medicine and Allied Sciences, Rajshahi, Bangladesh.

\section{Introduction}

\section{Case Report:}

This case was a 28 year old pregnant woman who came at this Institute in 1st September, 2016 for ultrasonographic evaluation of her pregnancy status. It was her second gravida. Her previous/first pregnancy was uneventful and age of her first child is five years. At her present pregnancy, she had complaint of pain in abdomen and excessive vomiting. Her abdominal size was unusually larger than usual. Size of her abdomen did not correspond with the stated period of her amenorrhea; fundal height was more. Her ultrasonographic evaluation was done at this institute at her 25 th week of gestation. This examination showed two fetuses in her uterine cavity with single placenta. One fetus was healthy and the fetal biometry of this fetus correlated with her stated period of amenorrhea. Other fetus showed different types of anomalies-like: trunk was very short, chest cavity was small, no neck and definite head was seen. Its upper limbs were also absent but lower limbs were larger and fatty.

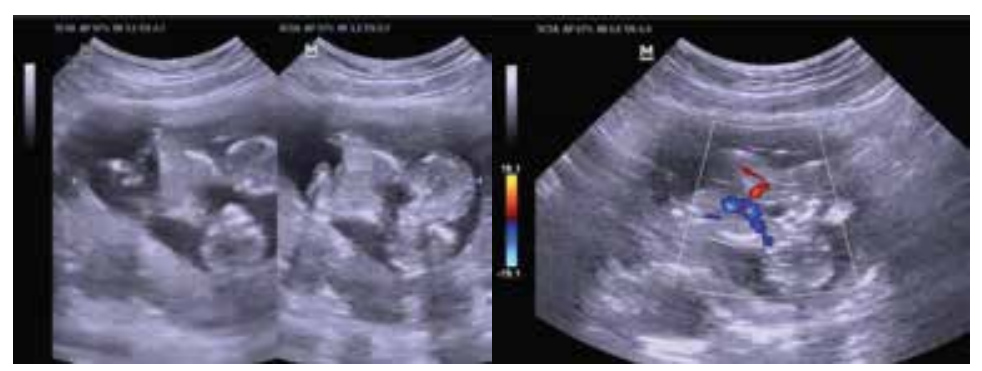

Figures 1: Ultrasound images of this case.

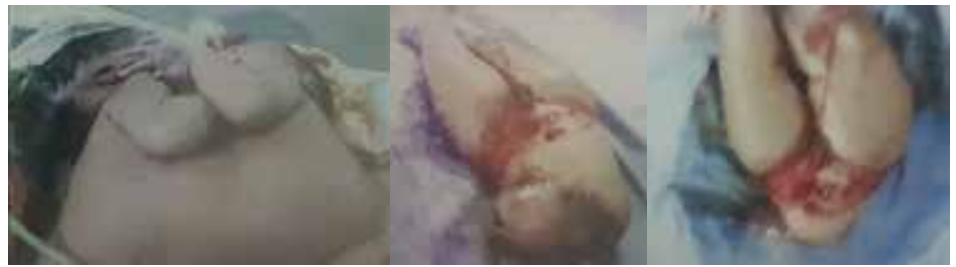

Figures 2: Images of this case (taken after delivery). 


\section{Discussion}

This condition of acardiac-acephalus twinning among the monochorionic twin pregnancies is a severe form of twin-to-twin transfusion syndrome (TTTS) ${ }^{1}$ (and severe TTTS has mortality rate of about $60-100 \%{ }^{2}$ ). In fact-in this condition, both normal fetus (which is termed as 'pump fetus'-as its heart pumps blood in both fetuses) and abnormal fetus (which is termed as 'recipient fetus'-as it receives blood from the normal fetus; it is also called 'acardiac or TRAP fetus'-as it has no heart of its own and shows reversed arterial perfusion) remain interconnected vascularly rather than having separate/independent circulation from the existing single placenta and abnormal fetal body lacks functional cardiac tissue along with absence of upper limbs and definite cranial part; this abnormal fetal part also shows reversed arterial perfusion through Doppler study of ultrasonographic examination. Moreover, due to hypoperfusion in 'acardiac fetus', different types of anomalies are seen-like: acardiac-acephalus (that is, no cephalic part and upper limbs are seen, only trunk and lower limbs are seen-as was present in this study case), acardiac-anceps (that is, partial cephalic part and upper limbs are seen; trunk and lower limbs are also seen-it is the highest developed form among the acardiac fetal cases), acardiac-acromus (that is, only cephalic part is seen but no trunk or limbs are seen-it is the rarest form of acardiac cases), acardiac-amorphus (that is, no recognizable human form is developed-it is the least developed form of acardiac cases) ${ }^{3}$. Regarding the pump fetus, if left untreated-these apparently normal fetuses die in $50-75 \%$ of cases $^{4}$. Underlying causes of this mortality are related to rapid growth of the acardiac fetus, polyhydramnios, heart failure of pump fetus due to high output. Also, the rate of fatality depends on the relative size of acardiac fetus. If size of acardiac fetus is greater than $50 \%$ of size of pump fetus, survival rate for pump fetus is only $10 \%$.

\section{Conclusion}

Having prevalence of about 1/35,000 overall pregnancies and accounting $1.0 \%$ of the monochorionic twin pregnancies $^{7}$, this rare case demands the early diagnosis through ultrasonographic examination routinely in the perinatal period worldwide so that the grave but preventable sequelae of monochorionic twin pregnancy related conditions can be managed early and effectively.

Conflict of Interest: None.

Acknowledgement

All the staffs of Ultrasonography section of INMAS, Rajshahi and special thanks to Dr. Nasrin Begum, Associate Professor, INMAS, Rajshahi for her active support during this article writing.

\section{References}

1. Knipe, Dr. Henry and Dr. Yuranga Weerakkody. "Twin reversed arterial perfusion". Radiopaedia.org. Retrieved 18 February 2016.

2. "Understanding the Stages of TTTS". UC San Diego. Retrieved April 23, 2012.

3. Van Allen MI, Smith DW, Shepard TH. Twin reversed arterial perfusion (TRAP) sequence: A study of 14 twin pregnancies with acardius. Semin Perinatol. 1983; 7:285-93

4. "Twin Reversed Arterial Perfusion Sequence (TRAP Sequence)". The Children's Hospital of Philadelphia. Retrieved 18 February 2016.

5. "TRAP Sequence or Acardiac Twin". The Fetal Treatment Center. UCSF Benioff Children's Hospital. Retrieved 18 February 2016.

6. "Twin Reversed Arterial Perfusion Sequence". C.S. Mott Children's Hospital. University of Michigan Health System. Retrieved 18 February 2016.

7. Chandramouly M, Namitha. "Case series: TRAP sequence". The Indian Journal of Radiology \& Imaging. February 2009; 19 (1): 81-3.

https://doi.org/10.4103/0971-3026.45352

PMid:19774147 PMCid:PMC2747410 